\title{
CARACTERIZAÇÃO MORFOLÓGICA E IDENTIFICAÇÃO MOLECULAR DOS ISOLADOS DOS NÓDULOS DE DALBERGIA NIGRA (VELL.) ALLEMÃO EX BENTH (LEGUMINOSAE - PAPILIONOIDEAE) DO SEMIÁRIDO DA BAHIA.
}

\author{
Pollyana Lopes Valle ${ }^{1}$; Aristóteles Góes Neto ${ }^{2}$; Gisele Santos Pinto Rocha ${ }^{3}$ \\ 1. Bolsista PIBIC/CNPq, Graduando em Bacharelado em Ciências Biológicas, Universidade Estadual de Feira de \\ Santana, e-mail: lopes.valle@gmail.com \\ 2. Aristóteles Góes Neto, Departamento de Ciências Biológicas, Universidade Estadual de Feira de Santana, e-mail: \\ arigoesneto@gmail.com \\ 3. Participante do projeto, Departamento de Ciências biológicas, Universidade Estadual de Feira de Santana, e-mail: \\ giseleuefs@gmail.com
}

PALAVRAS-CHAVE: rizóbios; diversidade; Dalbergia nigra

\section{INTRODUÇÃOO}

Segundo Souza (2010), as informações sobre a propriedade da nodulação e fixação de nitrogênio em muitas leguminosas são ainda escassas ou recentes e foram intensificadas nos últimos 30 anos, especialmente no Brasil. Pereira (2002) afirma que as leguminosas arbóreas perenes estão entre as espécies vegetais mais promissoras para a restauração de solos empobrecidos e erodidos, estas espécies não só protegem os solos, como também participam vantajosamente da ciclagem de nutrientes.

Dalbergia nigra (Vell.) Allemão ex Benth, conhecida popularmente como jacarandá-da-bahia, é uma arbórea tipicamente da Mata Atlântica, distribuída do sul da Bahia até o norte de São Paulo (CARVALHO, 1997). Esta espécie tem valor econômico extremamente alto, e é considerada a melhor madeira do Brasil para construção civil e fabricação de móveis finos e instrumentos musicais (CNC FLORA, 2015). No entanto, a Dalbergia nigra encontra-se na lista de espécimes ameaçadas de extinção devido à alta exploração da madeira e a devastação do seu hábitat natural. A falta de interesse no plantio do jacarandá-da-bahia é principalmente consequência da ideia difundida sobre o seu crescimento, considerado lento. Entretanto, devem ser efetuados estudos sobre essa espécie tendo em vista o elevado valor da madeira e o fato dela pertencer à familia Leguminosae cujos representantes, normalmente, apresentam capacidade de nodular (GALVÃO et al., 1979).

$\mathrm{O}$ uso de plantas associadas a micro-organismos na recuperação de áreas degradadas enriquece a fertilidade do solo e favorece a sucessão vegetal. $O$ uso de espécies da familia Leguminosae é uma boa alternativa, pois tem ampla representatividade no território brasileiro devido sua grande diversidade de espécies (UCHÔAS; FARIA, 2006). As leguminosas arbóreas nativas representam um potencial inexplorado, devido ao desconhecimento de suas características silviculturais, sua produtividade e, principalmente, sua habilidade em associar-se a bactérias fixadoras de nitrogênio.

Deste modo, o presente trabalho apresentou um caráter ecológico, econômico e biotecnológico relevante, pois estudou as bactérias fixadoras de nitrogênio isoladas a partir dos nódulos de Dalbergia nigra, caracterizando morfologicamente as colônias e identificando molecularmente algumas caractéristicas destes isolados, servindo assim, 
como base para futuros testes quanto à capacidade de acelerar o processo de sucessão ecológica na recuperação de áreas degradadas do semiárido.

\section{MATERIAL E MÉTODOS}

No Laboratório de Pesquisa em Microbiologia da Universidade Estadual de Feira de Santana (LAPEM / UEFS), os nódulos foram desinfestados com álcool etílico $95 \%$ por $30 \mathrm{~s}$ e hipoclorito comercial por $5 \mathrm{~min}$, sendo lavados com água destilada estéril por 6 vezes, durante $30 \mathrm{~s}$ em cada lavagem. Foram feitos cortes transversais nos nódulos inoculando-se os micro-organismos em placas de Petri contendo meio de cultura 79 sólido, comumente utilizado para crescimento de rizóbio (FRED; WAKSMAN, 1928), colocando a porção interior do nódulo seccionado sobre o meio de cultura. As placas foram incubadas a temperatura de $28{ }^{\circ} \mathrm{C}$ observando diariamente $\mathrm{o}$ crescimento das colônias por um período de 10 dias para permitir o aparecimento tanto de bactérias de crescimento lento, como as de crescimento rápido e intermediário. Após o crescimento inicial, as colônias morfologicamente distintas foram isoladas, transferindo-as para outra placa com meio 79, realizando repiques sucessivos para obtenção dos isolados. Posteriormente realizou-se a coloração de Gram e caracterização morfológica observando-se tempo de crescimento da colônia em horas, cor, mudança de pH no meio, produção de muco, presença de brilho, forma da borda, elevação da colônia e aparência.

A partir das colônias selecionadas, com base nas características morfológicas, a extração do material genômico foi realizada utilizando o protocolo de Edwards et al. (1991) com algumas modificações. O DNA genômico dos isolados foi amplificado usando os seguintes oligonucleotídeos iniciadores para reação em cadeia da polimerase (PCR): $\quad 16 \mathrm{Sf} \quad$ (5- AGAGTTTGATCCTGGCTCAG-3) e $16 \mathrm{Sr} \quad$ (5AAGGAGGTGATCCAGCC-3) universais (WEISBURG et al., 1991), que amplificam praticamente toda a região do DNA que codifica o gene $16 \mathrm{~S}$ rRNA. Para os alfarizóbios, fragmentos de $930 \mathrm{pb}$ de $\operatorname{nodC}$ foram amplificados usando os primers nodCf-Rizo (5'-AYGTH GTYGAYGACGGTTC-3') e nodCr-Rizo (5'CGYGACAGCCANTCKCTATTG-3') (BONTEMPS et al., 2010) por 30 ciclos de $30 \mathrm{~s}$ a $95{ }^{\circ} \mathrm{C}$, anelamento por $30 \mathrm{~s}$ a $58{ }^{\circ} \mathrm{C}$ e extensão a $72{ }^{\circ} \mathrm{C}$ por $45 \mathrm{~s}$, com uma extensão final de $5 \mathrm{~min}$ a $72{ }^{\circ} \mathrm{C}$. Tanto para alfa como para betarizóbios, ca. de $440 \mathrm{pb}$ foram obtidos do gene nifH usando os primers nifHf (5'-AARGGNGGNATYGGHAARTC3') e nifHr (5'-GCRTAVAKNGCCAT CATYTC-3') (CHEN et al., 2003). A amplificação do PCR dos fragmentos dos genes $\operatorname{nod} \mathrm{C}$ e nif $\mathrm{H}$ foi observada por meio de eletroforese em gel de agarose a $1 \%$.

\section{RESULTADOS E DISCUSSÃO}

Foram realizadas duas coletas a primeira do dia 21 de agosto de 2015 e a segunda no dia 07 de janeiro de 2016 no campus da UEFS. Para obtenção dos nódulos, a serrapilheira foi removida cuidadosamente para não danificar as raízes e, de raízes secundárias, foram destacados os nódulos. Os nódulos coletados apresentaram formato globuloso sendo caracterizados como nódulos de crescimento determinado (SPRENT, 2001). Os nódulos tinham forma arredondada, apresentaram coloração externa amareloamarronzado, tamanho variando entre 1 a $2 \mathrm{~mm}$, e coloração interna avermelhada no 
centro do nódulo (devido à presença da leg-hemoglobina), característica esta de nódulos ativos e jovens.

No total foram isoladas dezoito colônias $(n=18)$ das quais dez tornaram o meio de cultura alcalino, sete modificaram o meio tornando-o ácido e apenas uma colônia não modificou o pH do meio (Tabela 1), essa leitura é possível graças ao azul de bromotimol que é um indicador de $\mathrm{pH}$ presente no meio 79 .

Tabela 1: Caracterização morfológica dos isolados.

\begin{tabular}{|c|c|c|c|c|c|c|c|c|c|c|}
\hline Identificaçāo & Tempo de crescimento & Morfologia & Gram & Cor & Forma & Brilho & Prod. de muto & Elevaçప̆o & $\mathrm{pH}$ & Tam. da colốnia \\
\hline$A 02$ & $24 h s$ & bacilos grandes & positivo & amarelo daro & circular & + & + & cóncavo & àcido & $4 \mathrm{~mm}$ \\
\hline A04 & 24 hs & bacilos grandes & positivo & amarelo médio & circular & + & . & concawo & ácido & $2 \mathrm{~mm}$ \\
\hline$A 05$ & 7ahs & bacilos & negativo & branco leitaso & circular & + & + & cbcavo & básico & $1 \mathrm{~mm}$ \\
\hline $\mathrm{A} 08$ & 48hs & bacilo & negativo & amarelo & circular & + & + & coctwo & ácide & $0.5 \mathrm{~mm}$ \\
\hline A09 & Whs & bacilo & nepativo & amarelo leitoso & circular & • & + & Cincawo & ácido & $0.5 \mathrm{~mm}$ \\
\hline A10 & 4Shs & bascilo & negstivo & branco leitoso & circular & + & *4 & œōncervo & neutro & $0,5 \mathrm{~mm}$ \\
\hline A11 & 4Shs & cocos & negativo & branco leitoso & cirtular & + & + & obncarvo & busico & $0,5 \mathrm{~mm}$ \\
\hline A12 & 72hs & becilos longos & negativo & branco leitoso & circular & + & + & cóncavo & básico & $1 \mathrm{~mm}$ \\
\hline A13 & Ashs & bacilo & negativo & branco leitoso & circular & + & H & cóncaro & básico & $0,5 \mathrm{~mm}$ \\
\hline A14 & 48hs: & bacilo & negativo & amarelo médio & circular & + & + & cóncarvo & acido & $1 \mathrm{~mm}$ \\
\hline A15 & 48hs & bacilo & negativo & branco leitoso & circular & • & + & Lincervo & basico & $0,5 \mathrm{~mm}$ \\
\hline A16 & Ashs & bacilo longo & negativo & branco leitoso & circular & - & + & concervo & basico & $0,5 \mathrm{~mm}$ \\
\hline A1s & 4shs & bescilo & negativo & amarelo médio & circular & + & + & côncarvo & ácido & $1 \mathrm{~mm}$ \\
\hline $\cos A$ & 72hs & $\operatorname{cocos}$ & negativo & branco leitoso & circular & + & + & cóncarvo & bisico & $1 \mathrm{~mm}$ \\
\hline $\cos _{2} A_{1}$ & 72hs & coco bacilos & negativo & branco & circular & - & - & obncavo & básico & $0,5 \mathrm{~mm}$ \\
\hline$c 03$ & 7rhs & becilos longos & negativo & branco & circular & - & - & cäncavo & basico & $0,5 \mathrm{~mm}$ \\
\hline $\cos$ & This & bascilos longos & negativo & branco & circular & - & - & côncervo & básico & $0,5 \mathrm{~mm}$ \\
\hline $\mathrm{C} 13$ & 7zhs & $\operatorname{cocos}$ & negativos & amarelo & indeterminado & + & + & cóncavo & àcido & - \\
\hline
\end{tabular}

A maioria das estirpes isoladas tornou o meio alcalino e apresentou crescimento rápido, todas com elevação convexa e com formato circular, resultado semelhante aos obtidos por Silva et al. (2007) e Freitas et al. (2007) com rizóbios do semi-árido de Pernambuco. Os isolados são compatíveis quanto ao quesito de crescimento rápido afirmado por Sprent (1994) para estirpes de rizóbios tropicais.

Apenas dois isolados foram caracterizados como Gram positivos os quais foram desconsiderados como possíveis fixadores e noduladores, visto que segundo Moreira e Siqueira (2006) rizóbios são Gram-negativos e não formam arranjos.

Após a extração de DNA por meio do protocolo de Edwards et al. (1991) foi realizado o pcr da região com o kit Invitrogen® seguindo as recomendações do fabricante. As amostras que amplificaram a região $16 \mathrm{~S}$ foram as C02, C13, C03, A06, A08, A09, A13, A14, A18 (Fig. 1).

Vários genes estão envolvidos no processo de fixação de nitrogênio. Tais genes parecem estar organizados em clusters, exercendo cada um uma função específica relacionada ao processo de fixação e nodulação. Todos são importantes, mas pode-se citar os principais, que são os genes nif e nod (SANTOS, 2011).

Mothapo et al. (2013) propuseram a amplificação individual dos genes nif $\mathrm{H}$ e nodC como filtro para avaliação da capacidade diazotrófica e formação de nódulos de estirpes isoladas de nódulos, o que corrobora a metodologia aqui utilizada. Sendo assim, após amplificação da região 16s rDNA, as amostras estudadas foram selecionadas para amplificação da região nifH presente em todas as bactérias fixadoras de nitrogênio. 


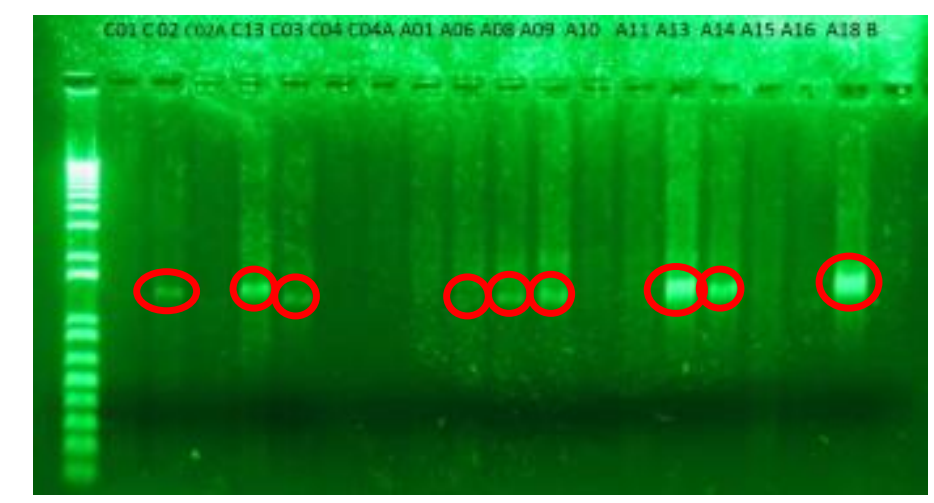

Figura 01. Gel de agarose $1 \%$ evidenciando a região $16 \mathrm{~S}$ rDNA amplificada.

A amplificação do gene nifH foi observada nos isolados A08, A09, A14, C13, A11 e A13, o que confere a estes isolados a capacidade de fixar nitrogênio. Segundo Moreira et al. (2010), os genes nif (nitrogen fixation) são genes requeridos para a estrutura, biossíntese e regulação da enzima nitrogenase e, portanto, encontrados em todos os diazotróficos.

Após a amplificação do gene nif $\mathrm{H}$, a presença do gene nodC foi avaliada e podese observar resultado positivo para as amostras A09 e C13 (Fig. 2), o que indica capacidade de nodulação para estes isolados (LEROUGE et al., 1990).

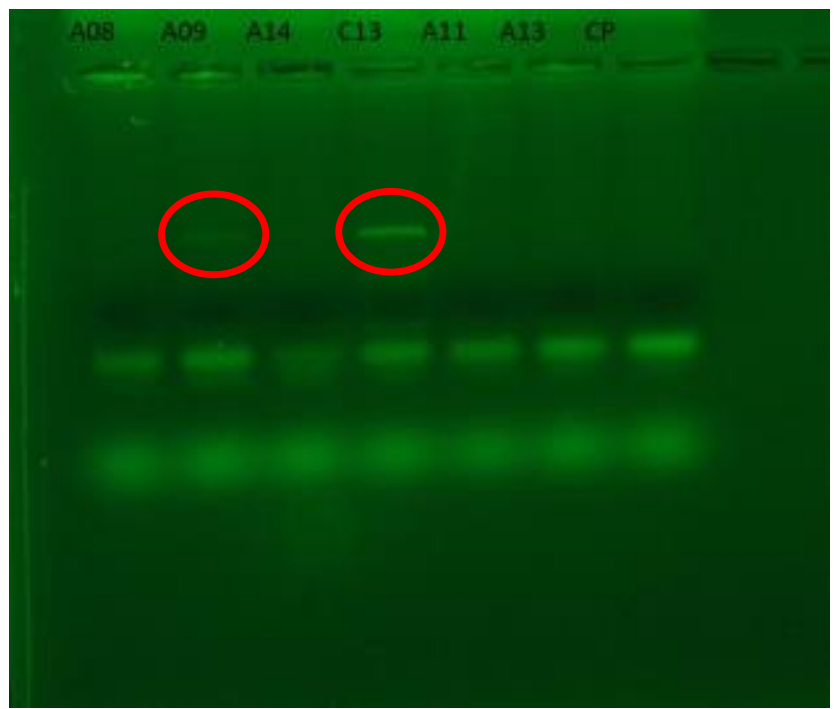

Figura 02 . Gel de agarose $1 \%$ evidenciando a região $\operatorname{nodC}$ amplificada para as amostras A9 e C13.

Os genes nod são encontrados em todas as espécies de rizóbio e são requeridos para a biossíntese de moléculas de lipooligossacarídeos ou oligossacarídeos lipoquitínicos, coletivamente chamados "fatores nod" (LEROUGE et al., 1990; LÓPEZ-LARA et al., 1995), estes "fatores nod" são responsáveis pela formação inicial do nódulo (LEROUGE et al., 1990).

\section{CONSIDERAÇÕES FINAIS}

Diante dos resultados aqui obtidos pode-se evidenciar uma diversidade morfológica de micro-organismos coletados dos nódulos de Dalbergia nigra onde a 
maioria dos isolados apresentaram crescimento rápido (1 a 2 dias) e capacidade de alcalinizar o meio. Com base nas amplificações obtidas (nif $\mathrm{H}$ e $\operatorname{nod} \mathrm{C}$ ), é possível afirmar a presença de rizóbios, pois os referidos genes são fundamentais para a fixação de nitrogênio e nodulação nas raízes das plantas estudadas. No entanto, estudos posteriores tornam-se necessários para investigação e identificação destes rizóbios presentes em Dalbergia nigra (Vell.) Allemão ex Benth.

\section{REFERÊNCIAS}

CARVALHO, A. M. DE. 1997. A synopsis of the genus Dalbergia (Fabaceae: Dalbergieae) in Brazil. Brittonia, 49(1), pp. 87-109.

CHEN, W. M., MOULIN, L., BONTEMPS, C., VANDAMME, P., BÉNA, G.; BOIVINMASSON, C. 2003. Legume symbiotic nitrogen fixation by - Proteobacteria is widespread in nature. Journal Bacteriology, 185, 7266-7272.

CNC FLORA, Centro Nacional de Conservação da Flora; Dalbergia nigra (Vell.) Allemão ex Benth. Disponível em: http//cncflora.jbrj.gov.br/portal/ptbr/profile/ Dalbergia\%20nigra. Acessado em: 07/04/2015.

EDWARDS K, JOHNSTONE C, THOMPSON C. 1991. A simple and rapid method for the preparation of plant genomic DNA for PCR analysis. Nucleic Acids Res 19: $1349 \mathrm{p}$. FRED, E. B.; WAKSMAN, S. A. 1928. Yeast extract-manitol agar. Laboratory Manual of General Microbiology. New York: McGraw-Hill, 145p.

FREITAS, A. D. S. et al. 2007. Caracterização de rizóbios isolados de Jacatupé cultivado em solo salino do Estado de Pernambuco, Brasil Bragantia. Campinas, v.66, n.3, p.497-504.

GALVÃO, A. P. M.; FERREIRA, C. A.; TEIXEIRA, L. B. 1979. Observações sobre o comportamento do jacarandá-da-Bahia (Dalbergia nigra fr. Allem.) em povoamento puro na Amazônia. IPEF n.19, p.47-59.

LEROUGE, P; ROCHE, P; FAUCHER, C; MAILLET, F; TRUCHET, G; PROMÉ, J. C; DÉNARIÉ, J. 1990. Symbiotic host-specificity of Rhizobium meliloti is determined by a sulphated and acylated glucosamine oligosaccharide signal. Nature 344: 781 784.

LÓPEZ-LARA, IM; VAN DER DRIFT, KMG; VAN BRUSSEL, AAN; HAVERKAMP, J; LUGTERBERG, BJJ; THOMAS-OATES, JE; SPAINK, HP. 1995. Induction of nodule primordial on Phaseolus and Acacia by lipo-chitin oligosaccharide nodulation signals from broadhost-range Rhizobium strain GRH2. Plant Mol. Biol. 29: 465-477.

MOREIRA, FMS; SIQUEIRA, JO. Microbiologia e Bioquímica do Solo. Lavras: Editora UFLA, 2 ed, 2006.

MOREIRA, FM.; SILVA, K.; NOBREGA, RSA.; CARVALHO, F. 2010. Bactérias diazotróficas associativas: diversidade, ecologia e potencial de aplicações. Comunicata Scientiae 1 (2): 74-99.

MOTHAPO, N; GROSSMAN, JM; MAUL, J. 2013. Genetic diversity of resident soil rhizobia isolated from nodules of distinct hairy vetch genotypes, Applied Soil Ecology, [Amsterdam], v. 64, p. 201-213.

PEREIRA, KC. Caracterização Morfológica, Bioquímica e Molecular de Rizóbios Recomendados para Inoculação de Leguminosas Arbóreas. 74p. Dissertação (mestrado). 
Universidade Estadual Paulista, Faculdade de Ciências Agrárias e Veterinárias. São Paulo - SP, 2002.

SANTOS, JMF. Diversidade de rizóbios isolados dos nódulos de Ormosia spp. e crescimento inicial das plantas. 61f. Dissertação (mestrado), Programa de Pósgraduação em Biologia e Biotecnologia de Micro-organismos, Universidade Estadual de Santa Cruz, Ilhéus - BA, 2011.

SILVA, VN; FIGUEIREDO, MVB; CARVALHO, FG; SILVA, MLRB. 2007. Caracterização e seleção de populações nativas de rizóbios de solo da região semi-árida de Pernambuco. Pesq Agropec Trop 37(1): 16-21.

SPRENT, JI. 1994. Evolution and diversity in the legume-rhizobium symbiosis: chaos theory?, Plant and soil 161:1-10.

SPRENT, JI. Nodulation in legumes. Kew, Royal Botanic Gardens. 146p. 2001.

SOUZA, LAG. 2010. Levantamento da Habilidade Nodulífera e Fixação Simbiótica de N2 nas Fabaceae da Região Amazônica. Enciclopedia Biosfera, Centro Científico Conhecer, Goiânia (GO), 6 (10): 1-11.

UCHÔAS, E. S.; FARIA, S. M. 2006. Seleção de estirpes de rizóbio para sansão preto (Mimosa sp), dormideira comprida (Mimosa quadrivalvis) e dormideira gigante (Mimosa sp). Leguminoas florestais com potencial uso na recuperação de áreas degradadas. Seropédica: Embrapa-Cnpab, 6 p. (Embrapa- Cnpab. Comunicado Técnico, n. 89).

WEISBURG WG, BARNS SM, PELLETIER DA, LANE DJ. 1991. 16S ribosomal DNA amplification for phylogenetic study. J Bacteriol 173:697- 703. 